Original Contribution

\title{
CHALLENGES OF THE APPLICATION OF LINGUISTIC KNOWLEDGE IN THE SPEECH PRACTICE OF THE ENGLISH LANGUAGE
}

\author{
Z. Zhelyazkova*
}

\author{
Faculty of Education, Trakia University, Stara Zagora, Bulgaria
}

\begin{abstract}
The article attempts to outline the main characteristics and topics of English language teaching in the most recent historical period in the development of Bulgaria. It envisages the last two decades, when intensive English language learning has become a priority, both social and institutional. Taking into account the nature of the language learning, the focus of interest is on the students' attitude to the subject, as well as the main difficulties experienced in the teacher-student interaction. The analysis of the data shows a balance between the teacher's intention and the learner's interpretation, which influences the end result - the actual mastery of the foreign language. The conclusion emphasizes the responsibility of the teacher to judge correctly what the student's expectations are, the freedom of variation that the curriculum gives them, as well as the practical implications of classroom processes for preparing the students for the outside world.
\end{abstract}

Key words: prior learner experience, plan and performance, teacher's professional qualities, active participation of the students

\section{INTRODUCTION}

In the vast variety of ideas and practices in teaching English, a basic competence that a teacher is called upon to develop is to be able to interpret theoretical language knowledge in accordance with the learner's speech needs. The experiences and understanding of foreign language learners and teachers differ significantly from the methodological prescriptions for the processes of teaching and learning a foreign language. However, if in the course of the learning process students become aware that knowledge of the language system provides them with a means to communicate in a foreign language and to participate in real life situations, they perceive this activity more effectively. Given the nature of foreign language teaching, the more important study seems to be the "naturalistic" study rather than the experimental methodology. Teachers and students know very well what the practical dimensions of theoretical knowledge are, while, on the other hand, researchers,

\footnotetext{
*Correspondence to: Zlatka Zhelyazkova Faculty of Education, Trakia University - Stara Zagora, Bulgaria, zlato6ki@abv.bg
}

curriculum designers and policy makers skillfully justify abstract formulations of classroom education. The latter often miss something essential: to link the acquisition of linguistic knowledge with the acquisition of competences, i.e. with their application in the real speech practice of the trainees. This gap leads to inconsistencies in the achievement of the ultimate goals and results in foreign language learning. This discrepancy can lead to different perspectives on what teaching is and what is important in it. Often there is a discrepancy between research and actual teaching. In order to overcome this gap and to fully understand teaching, it is necessary to take an approach that puts the main focus on the subjects of the learning process, that is, the students themselves. The important question to be asked is: what professional competence do teachers have to acquire in order to achieve the set goals? (1-3). The question is key in the intersection of how teachers are prepared, how professional studies are conducted, how teaching materials are developed and how meaningful educational policy is generated. What teachers know and how this knowledge finds its way into their practice is crucial for 
those who want to understand and influence education. It is necessary for the makers of foreign language education policies to be aware of the competence of foreign language teachers and the ways in which it can be put it into practice.

\section{DISCUSSION}

The Faculty of Education at Trakia University aims to create modern conditions for acquiring professional competence and competitiveness in the labor market. The training is performed by highly qualified academic staff and provides young professionals with solid scientific educational and practical training in both major educational and qualification levels. All major specialties receive varying levels of proficiency in English, which is highly recognized as a necessity in both social and institutionalized curricula. The renewal of the educational system and the implementation of innovative approaches are aimed at shaping the creative personality which develops, communicates and realizes its potential in a multi-dimensional and changing society (4). The great challenge for the trainers is not only to ensure that they have a good command of the foreign language, but also to prepare future teachers to acquire all the necessary knowledge and skills for their practical work in the classroom. In trying to understand the teaching profession, we are aware that teaching is generally viewed as the execution of certain activities and the pursuit of certain behaviors that lead to the necessary competencies so that those who are now learners are able to effectively educate their future students when they become teachers and educators. In other words, teaching is seen as a learning process that links the behavior of the teacher to the learning outcomes of the activity of the students (5-7).

\section{PLANNING AND ITS PRACTICAL IMPLEMENTATION}

The cognitive view of teaching views it as a combination of thought and action. Assuming teaching has a cognitive component, the logical question we ask ourselves is: What does the teacher know? How is his knowledge organized? How does the knowledge that the teacher has in his or her head actions influence their actions? After all, it is the subjective knowledge associated with the teacher that determines, for the most part, what happens in the classroom. English teachers, like all other teachers, always put into practice the strategies and techniques they used when they were doing their own learning. The quality of this process depends on whether the teacher can "express", put into practice his or her knowledge. The lesson planning process exemplifies this cognitive orientation for understanding teaching. When students learn how to plan their lessons, the first thing they are usually getting familiar with is the concept of the purpose of the lesson, followed by clarifying the content they are going to teach and linking that content to the appropriate activities. In this way, future or beginning teachers learn to plan their activities, they are being helped to organize their activities, to decide what they will do in their lessons and determine which actions will fulfill their goals in the most efficient and accessible way for the students. Planned in this way, the lessons include theoretical knowledge of language concepts and their direction towards the final results of the learning activity. When starting the implementation of the planned activities in the classroom, the beginning teachers encounter difficulties in the practical interpretation of the set theoretical assumptions. This whole process is based on the assumption that well-trained teacher professionals move from goals to actions and this makes their activity effective and, accordingly, their lessons successful. In the late 1970s, when teacher knowledge studies began to enter into the actual processes that teachers go through when planning and implementing their activities, interesting discoveries emerged. Twenty-two independent studies using different methods, summarized by Clark and Peterson (8) found that teachers did indeed plan their lessons, revealing a complex interaction between planning and plan implementation. Working largely within the decision-making process, this study reveals the connection between what teachers thought before class time, referred to as their preaction decisions and what they were thinking as they taught, referred to as their interactive decisions (decisions made during the action itself) (9). The researchers found out that it is not natural for teachers to plan in organized formats that they are taught to use. Even when they make a lesson plan in accordance with these formats, they often do not teach according to that plan. They are more likely to visualize the lessons as groups or series of activities. In other words, teachers tend to plan lessons as ways of doing activities for particular groups of students rather than 
achieving specific goals (10). "In my opinion, teaching is a complicated, messy job, and it is all about knowing what to do in the classroom," says one of the teachers interviewed (8, p. 109). In other words, one must "know the story in order to tell the story." Accepting the full complexity of classroom teaching requires that research in this area be reflected in curriculum development so that it becomes more accessible to teachers, i.e. it speaks their language.

\section{THE IDEA OF THE FLIPPED CLASSROOM}

A successful attempt to overcome the problem of the practical application of the principles of foreign language learning is the so-called by the theorists active learning and, accordingly, active teaching. It is grounded in the scientific research, according to which new generations of learners have new, fundamentally different characteristics:

- they are "addicted" to electronic devices and to communication in new social networks;

- they learn mainly through the use of new technologies;

- they seek what interests them in nontraditional ways, again with the help of modern technologies;

- they prefer to work in groups, in teams;

- they prefer to find the solution to a problem in a short way instead of listening to theoretical explanations;

- they find it difficult to keep their attention focused on the standard presentation of the lesson in the classroom, in other words, they could be defined as "goal-oriented";

- they tend to reuse items and watch videos showing how things happen.

Based on these psychological characteristics of the new learners, for whom images are the basis of perception of the world and knowledge, the so-called "inverted classroom training" is becoming more and more widely used in the pedagogical practice. It is an eclectic, blended learning experience whereby students are introduced to the content to be studied at their homes, as instructed by the teacher, using their technological devices, and then during a teacher-led school lesson together with their classmates (in teams) a series of actions guided by the teacher will lead to the achievement of the learning objectives, in our case - of learning a foreign language, to the acquisition of new language knowledge and skills. The image of the "mirror" illustrates the idea of this pedagogical practice as the reverse of the more common traditional practice of introducing new content at school and then assigning homework and projects to be carried out by students independently at home. The reversed model gives the opportunity to the students to take responsibility for their own learning; the amount of knowledge they can acquire, their skills level, the completeness and the linguistic accuracy become the responsibility of the trainees themselves. The challenge here is for teachers themselves to master the digital device skills needed to apply this new pedagogical practice (kahoot, animoto, scratch, panopto, etc.) (11).

\section{THE TEACHER-STUDENT INTERACTION}

The process of learning a foreign language involves a well-developed interaction between the teacher and the students. In the Bulgarian context, however, probably due to some national psychological characteristics, there is a general reluctance on the part of the students to actively participate in the exchange necessary for successful communication. Very often what is observed in the classroom is that no student takes the initiative to seek clarification or to get confirmation from a teacher about a hypothesis or even to ask a question. The problem of getting students to respond to the need for dialogue in the learning process (for their active participation) seems more acute for Bulgarian students than it is for Western European countries, and this is something with which Bulgarian teachers of English language must cope. In a survey performed by the author with high-school teachers who were asked to identify their biggest problem with teaching English (12), about seventy percent said that "getting a response" from their students was one of the biggest difficulties. The problem is even more aggravated by the fact that most of the educational course complexes used in English language teaching in the country are compiled by West European (mainly British) authors, in whose experience this problem is not of paramount importance. Even though they may be curious about learning and declare their good will to study English, the students seem to be unable to participate actively in class, while modern textbooks and aids, which are already predominantly communicative, focus on speaking and situational activities. The fear of making mistakes is cited as the main reason 
for this restraint. Most often, students have a habit of waiting to be "invited" to speak. In order to better understand the anxiety of learning a foreign language, it is necessary to understand language learning not only as a process of acquiring language skills and mastering rules or as participating in communicative activities, but also as a process in which individual learners are permanently placed in a vulnerable position in which they have to exhibit their own position and independence of thinking. This process is stressful and consequently creates a high level of anxiety for the students. These widespread phenomena are described as "a clearly distinguished complex of self-esteem, beliefs, feelings and behaviors related to language learning in the classroom, stemming from the uniqueness of the language learning process" (13, p.128). This uniqueness is based on the fact that students are required to "express themselves" in a language they do not speak well but are trying to master. This requirement influences the student's self-esteem and selfperception - "any representation in a second language is very likely to cause some inferiority complex in the individual as a competent communicator and lead to restraint, anxiety, fear or even panic" (13, p.128). When trying to communicate in a language they do not speak freely, however, trainees inevitably feel some vulnerability in presenting their personality and intelligence to others without dealing well with the unfamiliar means of expression that foreign language represents. The uniqueness of the language learning process lies in the fact that students are much more susceptible to criticism and negative evaluation than other subjects because the chances of errors in a foreign language lesson are much higher. The prevalence of anxiety in language learning in the classroom and how it affects their willingness to speak a foreign language in class are also highlighted in a survey conducted by freshmen in the specialty of Primary School Pedagogy with a Foreign Language at the Faculty of Education at Trakia University, Stara Zagora. Those who identify themselves as high-anxiety learners say they are afraid to speak a foreign language. Nearly half of those surveyed admit that they start to panic when they have to speak without preparation in the foreign language lessons. Nearly one-third say they are nervous and confused when they need to speak in class, and about half of the students surveyed say they feel confident when speaking a foreign language. About ten percent share a fear of being ridiculed by their peers and therefore prefer to move to the last row or even be absent from exercises in order to avoid "humiliation" or the inconvenience of being forced to speak (14). The factors identified by the students surveyed as contributing to the anxiety of learning English would logically affect their future students in the classroom. Students, as well as their own future students with a low command of English, systematically tend to Students, as well as their future English-speaking students, are systematically be prone to anxiety. Studies have shown that the level of anxiety of students with poor grades in English given by their teachers is much higher than that of those whose English is rated with good, very good or excellent results. What happens in the mind of the student is far beyond the reach of even the most brilliant teacher or researcher. Research in applied linguistics confirms that while the teacher may be able to control to some extent the experiences that the student is exposed to, it is ultimately the learner who "chooses" what and when to learn.

\section{CONCLUSION}

In order to successfully participate in English language practice, it is important for the teacher to link students' linguistic knowledge to its application in real-life situations. In this way, the teacher opens opportunities for practical application of the learning outcomes and supports the students' confidence in their knowledge. The interpretations of teachers' intentions often differ significantly from what teachers have in mind. The student's way of thinking has its own independence and there is often a huge gap between the ways in which teachers and students perceive what is happening in the classroom. To bridge this gap, it is important for teachers to constantly discuss with students why they are asked to perform certain activities. In the absence of such communication, trainees face the alternative of adopting a "survival orientation" (14, p. 26). In this case, they depend on external criteria - performing activities because the teacher has asked them to do so. As a result the students follow the teacher's guidance without in any way identifying themselves with it. In order for students to orient themselves towards achieving the language goals set, in order that they see the purpose of their participation in the activities, it is necessary for them to know why they are 
doing what they are doing. For the teacher, this means that he or she clarifies the goals of the activities at all times and, when necessary, "renegotiates" these with the students who are the actual subjects ot the educational process.

\section{REFERENCES}

1. Bruner, J. The Process of Education, Harvard University Press, 1977

2. Ertmer, P. A., Newby, T. J. Behaviorism, cognitivism, constructivism: Comparing critical features from an instructional design perspective. Performance improvement quarterly, 6(4). Wiley Online Library, 1993

3. Hmelo-Silver et al. Scaffolding and Achievement in Problem-Based and Inquiry Learning: A Response to Kirschner, Sweller, and Clark (2006). Educational Psychologist. 42 (2): 99-107, 2007

4. Tsenkova, A.K., L.K.Yordanova, G.G.Kirykova. Intercultural competence of a new type teacher. 4th International Forum on Teacher Education, IFTE, 2018

5. Piaget, J. The construction of reality in the child (Vol. 82). Routledge, 1955

6. Tobias, S. \& Duffy, T. M. Constructivist instruction: Success or failure? New York: Taylor \& Francis, 2009

7. Von Glasersfeld, E. Cognition, Construction of Knowledge, and Teaching.
Constructivism in Science Education. Springer, Dordrecht. pp. 11-308, 1998

8. Clark, C. M., Peterson, P. L. Teachers' thought processes. In: M. C. Wittrock (Ed.), Handbook of research on teaching (3rd ed., pp. 255-296). New York: Macmillan, 1986

9. Calderhead, J. A Psychological Approach on Teachers' Classroom Decision-Making. In: British educational Research Journal, Volume 7, Issue 1, pp. 51-57, 1981

10.Cooper, P. A. Paradigm Shifts in Designed Instruction: From Behaviorism to Cognitivism to Constructivism. Educational technology, 33(5), 12-19, 1993

11.University of Washington, Center for Teaching and Learning. Flipping the classroom - retrieved on 20.01. 2020 from: https://www.washington.edu/teaching/topic s/engaging-students-in-learning/flippingthe-classroom, 2020

12.Zhelyazkova, Zl. Effective acquisition of English Grammar. Stara Zagora, 2018

13.Hotwitz, E.K., M. Horwitz, J. Coper. Foreign Language Classroom Anxiety. The Modern Language Journal, 70, ii, 1986

14.Breen, M. Learner Contribution to Task Design. In: C. Candlin and D. Murphy eds. Language Learning Tasks, pp23-46), 1987 